\title{
Hybrid potato breeding: A framework for mapping contested socio- technical futures
}

\author{
Koen Beumer ${ }^{\mathrm{a}, \mathrm{b}, *}$, Rosanne Edelenbosch ${ }^{\mathrm{c}}$ \\ ${ }^{\text {a }}$ Copernicus Institute of Sustainable Development, Utrecht University, Utrecht, Netherlands \\ ${ }^{\mathrm{b}}$ Science and Society Group, University of Groningen, Groningen, Netherlands \\ ${ }^{\mathrm{c}}$ Rathenau Institute, The Hague, Netherlands
}

\section{A R T I C L E I N F O}

\section{Keywords:}

Socio-technical futures

Hybrid potato

Mapping framework

Unstructured settings

Contested expectations

\begin{abstract}
A B S T R A C T
This article characterizes the diverging expectations about hybrid potato breeding in the Netherlands. This potentially disruptive innovation for breeding new potato varieties has been subject to contested expectations, ranging from hybrid breeding amounting to nothing to it strongly upsetting the existing potato sector and bringing food security to developing countries. Literature in the sociology of expectations has highlighted that expectations are key in shaping the future of this innovation. In the case of hybrid potato breeding, these expectations are articulated in an unstructured setting, often within the walls of individual organizations. This makes an informed societal debate difficult. To aid the governance of expectations in unstructured settings, this article develops a mapping framework for expectations. Building on distinctions that emerged from the empirical material, stakeholders are positioned with respect to the expected impact of the innovation on the sector and on society. We found that stakeholders can be distributed along a clear curve that leads from low expectations for sector and society, to modest expectations for the sector and low expectations for society, to high expectations for both. This overview provides a basis for an informed societal debate and the articulation of socially robust expectations.
\end{abstract}

\section{Introduction}

In 2009, the Dutch start-up company Solynta (henceforth 'the start-up company') claimed to have developed a method for breeding diploid hybrid potatoes that can be propagated through seeds (Solynta, 2017). Traditionally, the development of a new potato variety happens through conventional crossings, which may take over twenty years to succeed, mostly because of the potato's genetically complex tetraploid genome. The technology developed by the Dutch start-up company promises to greatly increase the speed of breeding and makes it possible to develop potato varieties that can be propagated by seeds. The multiplication of potatoes currently happens vegetatively, by means of tubers, which are particularly susceptible to disease and expensive to transport.

The shift from conventional to hybrid breeding in other crops has historically been associated with a shift from breeding practices from the field to the greenhouse and the laboratory, increasing protection of knowledge, and commercial marketing of seeds around the world (Kloppenburg, 2004). As such, hybrid breeding has been part of a larger socio-technical transition of agriculture that saw the emergence of global agro-industrial production chains, the benefits and drawbacks of which have led to intense academic and societal debate. It is hence not surprising that hybrid potato breeding too has been subject to contested expectations, which range

\footnotetext{
* Corresponding author at: Copernicus Institute of Sustainable Development, Utrecht University, Utrecht, Netherlands.

E-mail address: k.beumer@uu.nl (K. Beumer).
} 
from hybrid breeding amounting to nothing to it strongly upsetting the existing potato sector and bringing food security to impoverished communities in developing countries.

Since the late 1990s, a growing body of literature has emphasized the performativity of expectations (e.g. Brown, 2003; Brown \& Michael, 2003; Borup, Brown, Konrad, \& Van Lente, 2006; Michael, 2000; van Lente \& Rip, 1998). Scholars in the sociology of expectations, the sociology of the future, and future studies have demonstrated that expectations are not merely neutral observations but that these predictions actively contribute to shaping the future: the governance of the future by expectations. This has provided further insight into the various ways in which claims about the future are strategically employed by different actors and how claims about the future are subsequently contested by actors with different views and stakes in the future: the governance of expectations (Konrad \& Alvial Palavicino, 2017).

Recognizing the importance of expectations in shaping the future (governance by expectations), various structured settings have been developed that aim to include the knowledge and perspectives of actors that are differently affected by the various futures that are at stake (governance of expectations). Such structured settings - like foresight exercises, scenario workshops, or panel debates enable different views and values to become visible. This may in turn inform the articulation of more inclusive expectations that take into account the views of diverging actors. In the case of hybrid potatoes, however, expectations are situated in a highly unstructured setting. Expectations about hybrid potato breeding are articulated in an ad hoc manner and in rather unconnected forums. Occasionally expectations have been put forward in the public arena (for example, see van der Lee, 2016) but mostly they have remained within the walls of individual organizations. This prevents an informed societal debate from occurring about this potentially transformative innovation and prevents individual actors from articulating more robust expectations that take into account the diverging assessments of other actors, which is widely considered as a crucial precondition for innovations to succeed.

What further complicates this situation is that existing methods for creating more structured settings to govern expectations may have rather high entry barriers, which is unlikely to be a unique situation. In the case of hybrid potato breeding, for example, several actors have highlighted that they are not willing to participate in time-consuming formal settings as they have no interest in defining a shared future (e.g. interview cooperation 30 January 2017). The result is that actors' expectations that inform their actions could be based on insufficient or erroneous information about the innovation in question and about the position of other actors. Unstructured settings may thus present a situation in which more insight into the diverging expectations of different actors can be beneficial but existing methods for governing expectations may not be feasible.

In this context, this article develops a mapping framework for potato expectations that can help to improve the governance of expectations in unstructured settings, which can provide the basis for an informed societal debate that can strengthen the articulation of socially robust expectations. Building on distinctions that emerged from the empirical material itself, stakeholders are placed in a framework based on the expected impact of the innovation on the sector and on society at large. This framework thereby can act as a guide for broadly mapping the different positions and interests that are at stake in diverging claims about the future impacts of hybrid potato breeding in particular, and other expectations in unstructured settings in general. It thereby builds on insights from Truffer, Voß, and Konrad, (2008) that such a framework can make it easier to understand what is at stake, which hurdles are perceived, and what drives or inhibits actors from acting upon particular expectations, thereby opening up space for assessing and reflecting upon expectations. Individual actors - including governments, scientists, companies and farmers - can use this knowledge of how other actors see the future in creating more robust expectations about the future of this potentially transformative innovation. The articulation of robust expectations that include a greater diversity of views, offers a strategic resource in mobilizing and coordinating the actions of different actors that play a role in the success or failure of innovation.

The next section outlines our methodology and sources, followed by a section that provides a further introduction to hybrid potato breeding and introduces the framework. Section 4 then discusses the different expectations actors have along the lines of this framework. In concluding, we highlight how mapping the different positions of actors in this way can provide a better understanding of the governance of potato innovation by attending to the governance of and by expectations.

\section{Concepts, theory, methodology and sources}

Our starting point is the concept of the governance of and by expectations (Konrad \& Alvial Palavicino, 2017). This notion summarizes a particular approach to understanding claims about the future that emphasizes the performativity of expectations: claims about the future have consequences for the present. For instance, claims about the benefits that a future technology can bring are not merely a prediction about the future but can spur actors into action in the present in an attempt to develop those technologies. Expectations are therefore critical resources in mobilizing funds, distributing roles, attracting allies, building shared agendas, managing uncertainty and assigning responsibilities and obligations (van Lente \& Rip, 1998; Brown \& Michael, 2003). And reversely, articulating a doomsday scenario is both a prediction as well as a call to arms to prevent that future from turning into reality (Nerlich \& Halliday, 2007; Tutton, 2011). This is referred to as the governance by expectations.

Because of the critical role that expectations play in mobilizing resources to realize futures, it should not come as a surprise that expectations are often highly contested. As Brown, Rapport and Webster noted: expectations "cannot be divorced from the situated lives of those contemplating them" (Brown, Rapport, \& Webster, 2000, p. 16). Actors often articulate competing views of what consequences future scientific and technological developments may have, each with different expectations about what technological developments will take place and what this will mean for the roles, responsibilities and obligations of different actors. Since the expectations articulated by both themselves and others are such an important mechanism for mobilizing resources, for actors enlisted in these futures it means that expectations themselves become subject to negotiation and coordination. The different modes through which expectations are negotiated and coordinated among actors is referred to as the governance of expectations. 
The perspective on expectations that we adopt here is mostly focused on technologically-induced change and draws upon insights from Science and Technology Studies. This field emphasizes that scientific, technological, and societal developments cannot be understood separate from each other (Bijker, 1995), and emphasises the situated nature of knowledge claims. The success or failure of innovations therefore depends on societal as much as technological factors. In studying the dynamics of expectations, we therefore do not only have to take into account various technological factors that different actors perceive to either inhibit or facilitate the success of hybrid potato breeding. Attention also has to be paid to societal aspects that inform the particular expectations about hybrid potatoes that are articulated by different actors, ranging from economic and practices to cultural norms, and from institutional structures to ethical values (e.g. see Brown et al., 2000; Borup et al., 2006; Selin, 2008).

In the case of hybrid breeding it is clear that expectations have already become performative. For one, the start-up company has received substantial government support and has licensed its technology to one of the largest potato breeding companies in the Netherlands. At the same time the socio-technical future of this technology is still very much contested among stakeholders. However, because the expectations are articulated in an ad hoc manner, in rather unconnected forums, oftentimes within the walls of individual organizations, it remains unclear what views and concerns underpin these diverging expectations. It is unclear whether the expectations of actors involved are sufficiently informed by a full understanding of the positions of other actors. In such unstructured settings (weak coordination of expectation), getting a clearer view of the different expectations can help actors to articulate more robust expectations that take into account the diverging assessments of other actors.

Our strategy for further probing different expectations in unstructured settings was to conduct semi-structured qualitative interviews with different stakeholders from inside and outside the Dutch potato sector. Exclusively relying on public statements is likely to be biased towards optimistic and strong expectations, as actors with moderate expectations may not feel the need to articulate these in public arenas, and as these are less prone to be covered by the media. Qualitative interviews also have several advantages over other mechanisms for eliciting expectations, especially when it comes to expectations in unstructured settings. Unlike interactive methods like foresight exercises or scenario workshops, where actors articulate expectations in relation to other actors present, qualitative interviews allow us to capture expectations of different actors in their own terms.

What is more, qualitative interviews are a relatively accessible method for mapping expectations in unstructured settings. The willingness by actors in the field to spend time and resources on organizing and participating in foresight and scenario activities largely depends on the existence of a shared agenda or at least the prospect of developing one, which often revolves around objectives like sustainability, competitiveness, or health. For instance, Truffer et al. (2008) developed a framework of expectations that is particularly suitable in conducting foresight processes aiming to create more widely shared expectations concerning sustainability transformations. The downside of this approach, however, is that this raises relatively high entry barriers for mapping expectations in contexts where several actors do not have a shared agenda because they expect the future is either not feasible or not desirable, which may often be the case in the context of unstructured settings. We have encountered this limitation during our fieldwork, as interviewees informed us that they were willing to participate in interviews but not in more formal and time-consuming settings as they have no interest in defining a shared future (e.g. interview large trading company 30 January 2017). Qualitative interviews lower this barrier substantially, thereby fitting well with our ambition to develop a rapid mapping tool for expectations.

We conducted 18 semi-structured interviews with stakeholders within and outside the Dutch potato breeding sector, including actors from governments and civil society organizations (see Table 1). In selecting interviewees, it was key to ensure a broad range of actors related to the innovation in question. The interviewees were identified on the basis of an elaborate literature review as well as an unpublished overview of relevant actors in the wide context of Dutch potato breeding (van Dijk, Edelenbosch, \& Beumer, 2016).

An interview guide was used to ensure comparability across interviewees while the open-ended nature of this interview method also allowed for probing deeper whenever this was deemed interesting. These interviews were systematically transcribed and

Table 1

List of interviewed actors.

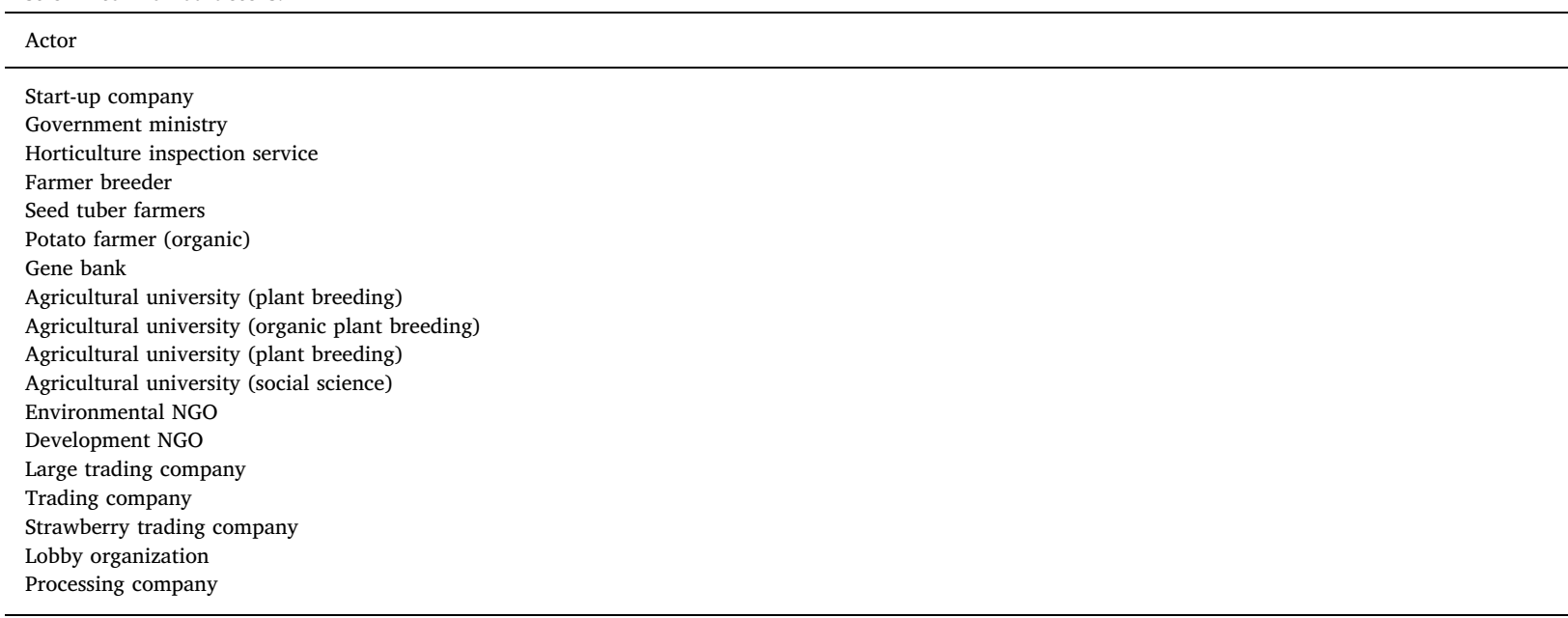


subsequently coded for different expectations concerning hybrid potatoes using Atlas.ti. This formed the basis for systematically analysing expectations on hybrid breeding by different actors, while attending to both technological factors and societal aspects that inform particular expectations about the future of hybrid potato breeding. We constructed the mapping framework on the basis of differences in the expectations that emerged from the material itself. Our interviews show how views about socio-technical futures are related to, and take shape in, different envisioned possibilities for social change and new social arrangements.

\section{Hybrid potato breeding and its context}

Before heading towards the framework of potato expectations, however, a little background is required to the existing practices and organization of potato breeding. The common principle of developing new potato varieties through conventional breeding methods is to cross two potato plants (parents) with different genetic backgrounds. Potatoes are genetically quite complex, having four sets of twelve chromosomes (hence they are tetraploid), and crossing two parents thus produced a great variety of different combinations in their offspring (e.g. for each gene you would get AaBbCcDd x AaBbCcDd). Breeders therefore start with about a million different seedlings for each crossing, which are then brought down to a few varieties by selecting the best contenders every growing season, a process which generally takes up to twenty years. The remaining varieties score high on a number of properties, including size and shape, dry matter content, cooking and baking quality, shelf life, taste, but also resistance to various diseases.

The practice of hybrid breeding that is currently developed by the start-up company strongly diverges from this. The principle of hybrid breeding is to cross a plant with itself, also called 'inbreeding', so as to produce offspring with more identical pairs of genes on both chromosome copies. This makes it possible to create a pure line, a plant which is completely homozygous, with two exact copies of all chromosomes. Crossing two homozygous plants (e.g. aabb x AABB) subsequently always produces the same offspring, ensuring the desirable properties are present. While inbreeding often results in degenerated offspring, the cross of two inbred parent lines produces remarkably strong plants. This phenomenon is known as hybrid vigour and it has been an important element in the spectacular increases in productivity in crops like corn, sugar beet, and tomato since the 1960s, which is at times referred to as the Green Revolution. The tetraploid potato genome makes creating homozygous inbred lines highly impractical but the start-up company developed a way to create diploid potatoes that can be used for hybrid breeding.

Potato is already a highly important crop. In terms of total production it is the fifth food crop of the world after sugarcane, maize, rice and wheat respectively, and the potential of potato as major food crop in the world is still growing (Food \& Agriculture Organization of the United Nations (FAO), 2015). Potatoes are grown in large numbers. In 2014, over 380 million tons of potato were produced globally, with the Netherlands producing 7.1 million tons (Food \& Agriculture Organization of the United Nations (FAO), 2015; Centraal Bureau voor de Statistiek (CBS, 2015). The potato is culturally and historically important for the Dutch, it being a traditional dinner staple, as illustrated by Van Gogh's 1885 painting of 'The potato eaters'. With regard to potato production, the Netherlands is mainly known for its largescale export of potato starting material, with the small country producing 53\% of the world's seed tubers (Rabobank, 2015), of which countries in North Africa and the Middle East are important buyers (Nederlandse Aardappel Organisatie, 2017).

In the Netherlands the breeding of new varieties is generally done by trading companies, although part of the selection process is outsourced to 'farmer breeders' with a keen 'breeder's eye' (Almekinders, Mertens, van Loon, \& Lammerts van Bueren, 2014). There are five large trading companies in the Netherlands and a few smaller ones and they coordinate the first part of the potato processing chain and thereby ensure that farmers grow their licensed varieties (de Vriend \& Lammerts van Bueren, 2014). In order to grow potatoes, farmers do not use seeds but tubers as starting material. These tubers ${ }^{1}$ are cultivated and multiplied by specialized growers for up to seven years, after which potato farmers use them to cultivate potatoes for consumption or industrial processes. Each year of multiplication makes the tubers more susceptible to disease, so this multiplication is carefully monitored by a government inspection service.

Potatoes produced for consumption, 'ware' potatoes, are different from the starch potatoes produced for the starch industry. Ware potatoes find their way to potato processors, quick service restaurants (QSR) and retailers in about equal thirds. These companies control the second part of the consumption potato supply chain and have put in place tight contract agreements with potato producers. The starch production chain is controlled by one large cooperation from beginning to end. Tuber, ware and starch potatoes contributed for $25.6 \%, 47.6 \%$, and $26.7 \%$ of the Dutch acreage respectively (Centraal Bureau voor de Statistiek (CBS, 2015).

In this context, hybrid potato is promised to increase the speed and precision of breeding and to enable the propagation of uniform potatoes through seeds. The significance of these developments, however, remains contested among stakeholders, who articulated diverging expectations about the impact these developments may or may not have.

\section{Mapping expectations for hybrid breeding}

In the following, we therefore identify patterns in the expectations articulated by these different actors in unstructured settings, and we will examine these differences in the light of the positions these actors hold, both in relation to the technology in question and in relation to various societal aspects that inform these expectations, as was outlined in the theory section. We mapped the different stakeholders along the lines of two axes that immediately stood out from the empirical material: the expected impact on the potato

\footnotetext{
${ }^{1}$ Tubers are generally called 'seed tubers', even though they are not seed: tubers are the storage organs of the potato plant that can also act as a clonal propagation mechanism.
} 


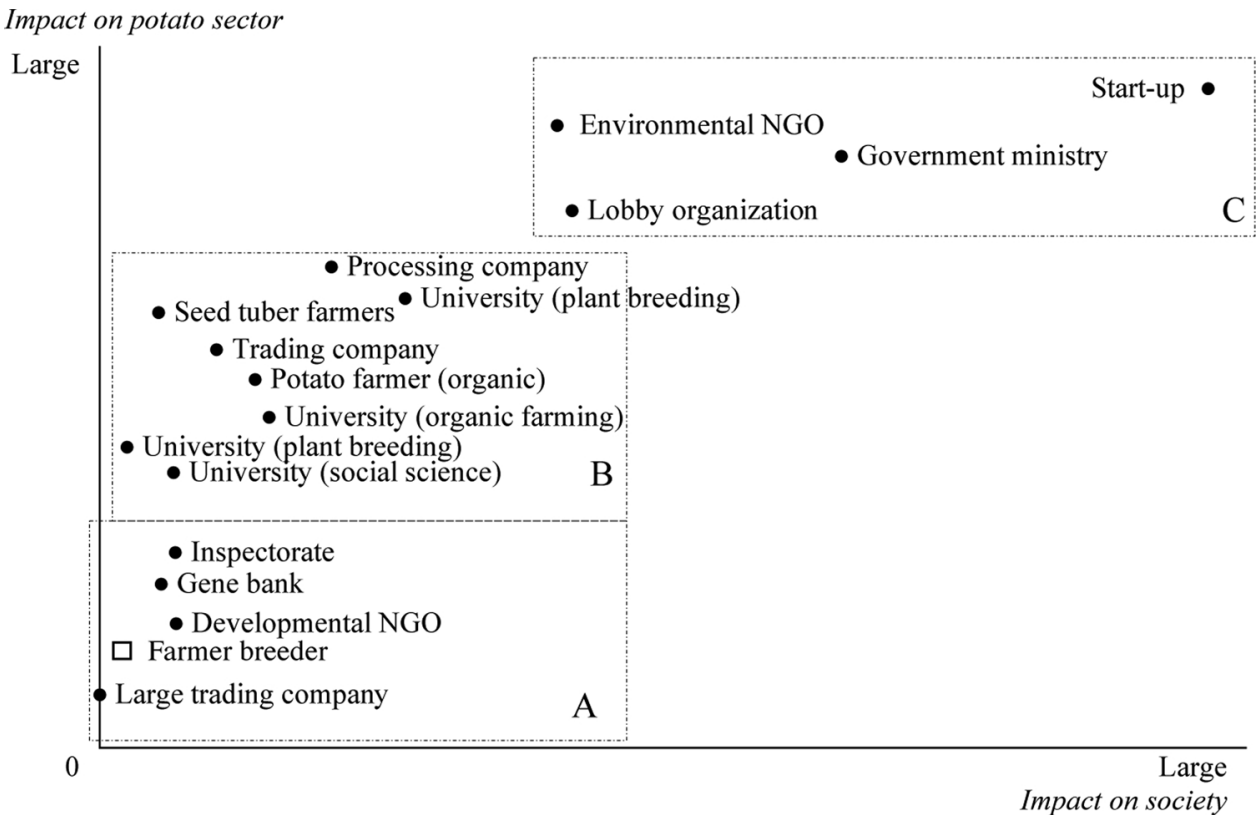

Fig. 1. Framework for mapping actors' hybrid potato expectations.

sector and the expected impact on society (Fig. 1). Both axes should be understood as a spectrum. The expected impact on the potato sector ranges from none to large, with the actor with the most limited expectations foreseeing no impact whatsoever, whereas the actor with largest expectations foresees a complete disruption of the entire sector, both in terms of breeding practices, actors, and organizational structure. The expected impact on society also ranges from no impact at all to a large impact, for instance with regard to issues such as sustainability and global food security.

Both scales further have to be understood as relative. Whereas a fixed criterion can be identified for the bottom-left (no impact on sector and society), we did not use a predetermined criterion for determining larger expectations. Instead the actors have been positioned in the framework relative to one another, with the actor having the highest expectations for sector and society situated on the top right. We stress that the mapping of actors is not an exact science- the framework serves as a tool for researchers to visualize the actors' relative positions, giving an overview of their expectations and also making it possible to discover patterns here.

We will discuss the different stakeholder positions in three parts, by following the curve that became visible when we mapped their positions (Fig. 1). First we will discuss expectations of stakeholders that expect hybrid breeding to have limited to no impact on either the potato sector or society at large (box A, bottom left). Next we will discuss expectations of those stakeholders that expect a greater impact on the sector and moderate to medium impact on society (box B, left center and center). And finally we will discuss actors that have high expectations both in terms of sectoral and societal impact (box $\mathrm{C}$, top right).

\subsection{Low expectations for the sector, low for society}

\subsubsection{Low expectations for the sector}

The actors positioned at the bottom left of the framework do not expect hybrid breeding to have much impact on the potato sector. The actor we find furthest to the bottom is the representative of the large trading company, followed by the farmer breeder. The trading company representative was skeptical that hybrid breeding will amount to anything, even doubting the most modest expectations articulated by others. The other actors positioned here, however - the developmental NGO, the farmer breeder, the gene bank, and the inspectorate - did see some kind of future for this innovation, but they generally expect there to be too manyfactors that will prevent hybrid breeding to bring about any significant change.

These actors identified both societal and technological factors that they expect will prevent hybrid breeding from having an impact on the existing sector. The most important technological barrier was the expectation that growing potatoes directly from seed will not be feasible in the near future. The gene bank representative for instance argued that seed will not yield sufficiently sized potatoes and that tubers have the advantage that farmers can plant the tubers sooner as they are robust enough to withstand the harsher conditions early in the growing season (interview 26 February 2017). Also, the expectation that hybrid breeding can contribute to faster and more precise breeding was questioned on technical grounds. For instance, these actors expected the yield and vigor of diploid material to stay behind as compared to tetraploid material (interview farmer breeder 28 July 2016 II, gene bank 26 February 2017). These interviewees expected this barrier would take many years or even decades to be overcome.

According to these actors, also various societal factors stand in the way of hybrid breeding having an impact on the potato sector. Different interviewees believed that even if hybrid breeding would make it possible to develop new varieties faster, this would nevertheless fail to increase the turnover rate of new varieties because the structure of the potato system would not allow it. For 


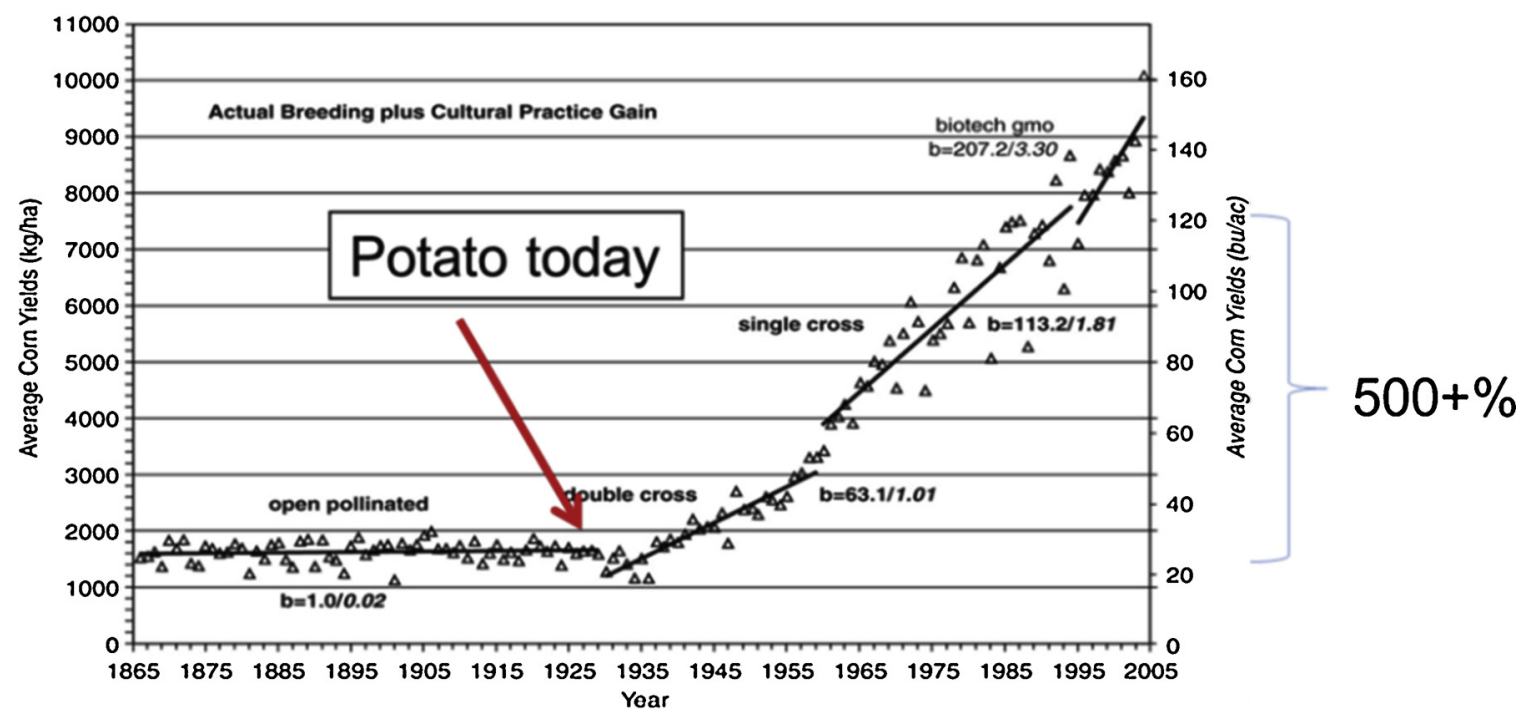

Fig. 2. Corn as example for the start-up company's $\mathrm{F}_{1}$ hybrid breeding.

instance, the large trading company pointed out that some of the most important Dutch markets for potatoes, like North Africa and the Middle East, are relatively conservative and simply do not want to cultivate or eat new varieties (interview 30 January 2017). Various interviews also highlighted that both farmers and processors cannot adapt to new varieties frequently as this requires both a lot of work (like adjusting machines) and the acquisition of new skills and (tacit) knowledge (interviews large trading company 30 January 2017, inspectorate 16 July 2016). So even if new varieties could be developed faster, this would have no significant impact on the sector.

The representative of the trading company situated at the bottom left of the framework, further expected that the technical requirement of collecting seeds by hand is financially unfeasible. He demonstrated this with an elaborate cost-benefit analysis, on the basis of which he expects that in even the most optimal situation (cheap Chinese labour, sowing with machines, high yields), hybrid seeds could not be made financially profitable. He further strengthened his arguments by pointing out that the start-up company keeps adjusting their expectations, pushing the release date further in time (see Fig. 2). Only in the most optimistic scenarios, so he concluded, hybrid breeding may become a niche market, breeding special varieties for culinary restaurants, or areas in the world where transportation is difficult, like Southern India (interview 30 January 2017). The farmer breeder has been positioned a bit higher because although he gave many arguments questioning the feasibility of hybrid breeding, he did expect hybrid breeding to make it simpler to include interesting genes from the wild gene pool (interview 28 July 2016 I).

\subsubsection{Low expectations for society}

The actors in the left bottom corner of the framework also expected that hybrid breeding will have either no or modest consequences beyond the potato sector, for instance concerning sustainability, farming systems, and food security. This should not come as a surprise, as these actors brought up many challenges related to the technological feasibility of hybrid breeding, and therefore had no expectations for the technology to impact upon society.

\subsection{Modest expectations for the sector, low to Modest for society}

\subsubsection{Modest expectations for the sector}

Following our curve further upwards, we see that many interviewees did expect hybrid breeding to at least have some impact on the sector. These actors include university researchers in social sciences, biological agriculture, and potato breeding, as well as a rival trading company, the seed tuber farmers, potato farmer, and the representative from a processing company.

None of these stakeholders expected hybrid breeding to entirely disrupt the existing sector. Like the stakeholders with the lowest expectations, they foresaw several technological obstacles to hybrid breeding that will prevent this from happening. Several of these barriers were also mentioned above, like the expectation that growing potatoes directly from seed will not yield sufficiently sized potatoes and that yields from diploid material will not match those from tetraploid material (interview tuber farmers 28 July 2016 II, university 15 June 2016). But also several other technical limitations were put forward. For example, the social scientist pointed out that past attempts to grow potatoes directly from seed have shown that seeds are much more vulnerable and require too many high inputs like fertilizers, mechanization, and irrigation (interview 1 July 2016). The trading company and the organic farmer furthermore argued that the change from tubers to seed would be too large a financial risk, as lower yields would immediately cause financial trouble (interviews 20 May 2016 \& 8 February 2017). And both the tuber farmers and the processing company expected hybrid breeding would not be able to produce truly uniform varieties from seed, as even diploid potato genes are too variable (interview farmer 28 July 2016 II), which could inhibit other companies from investing in the technology (interview processing 
company 22 April 2016). These limitations implied for these stakeholders that a vegetative multiplication phase would remain in place.

Whereas these interviewees thought it unlikely that potatoes will grow directly from seed, they did agree that hybrid breeding could eventually lead to less multiplication steps. Interviewees expected this to have different implications for the sector. The social scientist expected that if the number of generations required reduces, seed tuber farmers will enlarge their capacity (produce more), reduce costs, or specialize in different ways (interview university 1 July 2016). Others, such as a plant breeding researcher and the tuber farmers believed that part of the multiplication sector will eventually disappear (interviews 12 May 2016 \& 28 July 2016 II). These have been positioned higher on the map. And according to some, in order for hybrid potatoes to be a success in developing countries, a local seed multiplication system and infrastructure would have to be set up regardless of whether the multiplication phase would be shortened or not (interview processing company 22 April 2016).

Different interviewees further believed that hybrid breeding would make it possible to develop new varieties faster, enabling breeding companies to bring new and better varieties on the market almost every year. A university researcher of organic farming expected this will make the sector much more competitive, just like we have seen in the horticulture sector (interview 18 May 2016 ). All other interviewees in this part of the framework, however, did not expect the faster development to new varieties to affect the turnover rate of new varieties as this is prevented by various structural features of the potato system. Like stakeholders with the lowest expectations, various interviewees pointed out that adopting a new variety cannot proceed any faster because it requires quite some work in recalibrating tractors and processing machines (tuber farmers 28 July 2016 II, processing company 22 April 2016). The social scientist further argued there are logistical and financial limitations to the amount of varieties that trading companies can register, multiply, promote, and sell (interview 1 July 2016). And the processor representative even argued that a more robust potato would allow processing companies to make use of less varieties, because the risk of failed harvest of each variety decreases (interview 22 April 2016).

Central to moderate expectations about the impact of hybrid breeding on the sector is the idea that the sector itself is highly unchangeable. This is also reflected in the expectation of several interviewees that the most significant impact of hybrid breeding will be to strengthen the existing distribution of roles within the potato sector. Currently farmers are caught in the middle between the trading companies on the one end and at the other end the processors and retailers, who control much of the potato sector. Hybrid breeding is not expected to change this, as the organic farmer noted, especially since large multinationals may patent the new varieties from hybrid breeding, increasing the dependency of farmers on these companies even more (interview 8 February 2017). And even without patents, the university researcher of organic farming pointed out, hybrid breeding may increase the control of the beginning and end of the production chain because the parent lines can be considered to be a natural patent, which will become the most important asset of the breeding companies (interview 18 May 2016).

Furthermore, the few sectoral changes that these stakeholders expected to occur are not attributed to hybrid breeding alone. They argued the modest changes that hybrid breeding may bring merely strengthen existing trends. For instance, the trade company breeder argued hybrid breeding can be seen as one tool among many, such as marker assisted breeding (interviews 20 May 2016 ).

These interviewees thus believed that the turnover of new potato varieties is marked by a strong path dependency (David, 1985) on existing ways of breeding and processing potatoes. Interviewees often backed up their modest expectations with arguments referring to the past. In their long history in potato breeding, multiplication, and trade, they have seen a long list innovations fail and they have no incentive to expect things to be different now. They argued that a quick succession of varieties has never been witnessed in the past, pointed to the recent development of genetically modified late blight resistant potatoes that still have not managed to make it to the market, and made references to True Potato Seed, which has been around for some time but failed to make a sustained impact on potato breeding (e.g. interview university 12 May 2016; university 18 May 2016).

\subsubsection{Low to modest expectations for society}

Interestingly, the majority of actors with moderate expectations for the sector had very little expectations about the societal impact of hybrid breeding. In many cases, societal aspects were merely peripheral to their concerns, and thus did not feature prominently when they spoke about the future. We have seen this especially in relation to health issues or environmental issues. For instance, although interviewees in this part of the framework expected hybrid breeding may be used to develop disease resistant potatoes that are less dependent on pesticides, which could benefit the environment, environmental impact was not a part of their future visions. When asked about this, the processor representative explained that the carbon footprint is a 'soft' factor, important in light of societal pressures to use less chemicals, while selling products with sufficient profit margin is a 'hard' factor. Hard factors are what bring companies into motion (interview 22 April 2016).

Other actors had low societal expectations because they argued changes to society are too complex for hybrid breeding in itself to make a significant difference. Just like they expected the impact on the sector to be limited because the sector is highly pathdependent, so they expected hybrid breeding alone could only make a modest impact on complex systems whose propensity for change depends on a lot of different factors (e.g. interview developmental NGO 9 March 2017).

This is also true for stakeholders in this part of the framework that do expect some impact on society, and hence are situated slightly more to the right. These actors had quite diverse expectations, mostly about food security, and occasionally pertaining to sustainability and farming systems. Several interviewees for example foresaw modest negative impacts on food security. The smaller trade company breeder argued that for developing countries, hybrid breeding could increase risks of food insecurity because seeds are more vulnerable and can only be grown under highly specific conditions. For this reason, he did not believe hybrid breeding will make a large impact on food security (interview 20 May 2016). The organic potato researcher expected hybrid breeding may make farmers more dependent on large companies. However, she similarly expected this impact will be modest, as this would only be the 
case for about $2 \%$ of farmers who she could imagine becoming recurrent seed purchasers, as the great majority of potato farmers in developing countries still relies on informal seed systems (interview 18 May 2016). The social scientist, in contrast, thought that hybrid breeding could have a modest positive impact on food security. Hybrid breeding could contribute to making developing countries 'somewhat' less dependent on Dutch tubers, if these countries manage to build their own decentralized tuber multiplication systems. Multiplying tubers is difficult in Africa, but disease free starting material in the form of seeds would help to overcome some challenges (interview 1 July 2016).

The organic farmer and the organic potato researcher are also positioned here. Their main societal expectation was that hybrid breeding may contribute to the existing trend towards large monocultures. While in their view this is certainly not set in stone, they expected this might occur in two specific circumstances: either in case a large multinational corporation gains ownership over hybrid breeding, as they are more likely to develop varieties that are suitable to large monocultures. Or in case the potato sector becomes more like the horticulture sector, in which breeding is becoming increasingly expensive, which translates into the price of seed and stimulates farmers to produce monocultures. The organic farmer underlined his view by arguing that the world can in principle be fed through organic farming, but that things would have to be done radically differently. Hybrid breeding, from the perspective of both interviewees from the organic sector, is a technological fix that fits well with the existing farming system, and it therefore unlikely to bring larger societal changes (interviews 8 February 2017 \&18 May 2016).

What all these interviewees share is the expectation that hybrid breeding alone cannot overcome systemic barriers and that the only changes that can be brought about are those that fit with larger trends that have already been set in motion.

\subsection{High expectations for the sector, high for society}

\subsubsection{High expectations for the sector}

Finally, at the end of the curve, at the top of our framework, we find a small number of actors with very high expectations for hybrid breeding on the sector. They have described hybrid breeding as a 'game changer' (interview government 29 July 2016 ), as a 'paradigm shift' (Solynta, 2016a), and as a 'revolutionary technique' that can 'reset' the potato chain the Netherlands and 'change the power balance in the entire sector' (interview environmental NGO 15 July 2016). We positioned the start-up company in the top right corner, because they are the only interviewee who expects farmers to directly start growing True Potato Seeds, thereby shortening the multiplication of potatoes from five to ten years to a single planting season. This will virtually eliminate the entire potato multiplication chain and open up new markets by drastically lowering transport bulk and costs.

Other actors with high expectations focused more on the increased speed and precision of breeding as the cause of creative destruction in the sector. Actors like the government, the lobby organization, the environmental NGO and of course the start-up company itself, expected hybrid breeding to enable new varieties to be developed much faster than with convention breeding techniques. Conventional breeding by crossing tetraploid parents is a time-consuming ordeal, in their view, as it takes some 15 years at least. These actors expected hybrid breeding with diploid varieties to reduce this time to some two to three years. And once a sufficient number of inbred parental lines have been created, one can combine different properties with greater precision (interviews 29 July 2016, 23 June 2016, 15 July 2016 \& 29 March 2016). The start-up has illustrated this expectation in numerous presentations at conferences and workshops with Table 2.

Actors with high expectations often drew upon the comparison with vegetable breeding in outlining the expected consequences of faster and more precise breeding. Once potatoes can be bred as hybrids, so these actors assume, they will be sufficiently similar to other crops so as to take mimic events occurring in other sectors. The government official for example highlighted that a much broader assortment of tomatoes has become available after hybrid breeding was introduced in tomatoes some thirty or forty years ago and "that is exactly what we expect with potatoes" (interview 29 July 2016). The start-up company, whose main researchers themselves started their careers in hybrid tomato breeding, expected that "probably potatoes will take the same route as the vegetable sector" (interview 29 March 2016).

According to these interviewees, this would imply a complete change in breeding practices, with potentially large consequences for actors currently operating in the potato sector. Some interviewees expected all companies to start using hybrid breeding, thus requiring different skills and investments, producing different relations between actors in the sector. For instance, the lobby organization expected breeding companies to become more specialized and to become less dependent on trading companies as they will be able to respond more rapidly to new developments (interview 23 June 2016), just like the start-up company itself expected

Table 2

Hybrid potato breeding expectations by the start-up company.

\begin{tabular}{|c|c|c|}
\hline & Traditional breeding & Hybrid breeding \\
\hline Introduction one trait & $15-50$ years & $2-3$ years \\
\hline Trait stacking & impossible $(>>100 y)$ & Feasible in $3-7$ years \\
\hline Phytophthora resistance & $>50$ years & 4 years \\
\hline Multiplication & vegetative $(5-10 \mathrm{y})$ & seeds (one season) \\
\hline Seed health & contaminated & Clean \\
\hline Conclusion & Russet Burbank is leading variety for 137 years & $\begin{array}{l}\text { Dynamic introductions of innovative products } \\
\text { Value creation } \\
\text { Disruptive change }\end{array}$ \\
\hline
\end{tabular}


breeding to become cheaper, with breeding companies subsequently having to spend relatively more on overhead and research and development (interview 29 March 2016).

Some actors are even expected to disappear from the sector entirely. For example, the government official expected that hybrid breeding may be the end of the profession of "farmer breeder". He said the government will only ensure a level playing field and will not intervene in case hybrid breeding will have detrimental effects for farmer breeders, noting that "that's the way the world works" (interview 29 July 2016). And the start-up company itself noted that those who will not join this development will eventually lose out:

"One could call this the Kodak effect. They say 'we are the largest in the business and this is the way we work' and when a new innovation emerges they do not adopt it. Then they can go bankrupt. That it is not my intention, but well, if that is their policy, then it could happen" (interview 29 March 2016).

In several conference presentations, the start-up company also drew upon the analogy with hybrid corn, loosely suggesting that a yield increase of up to $500 \%$ may be possible (see Fig. 2). This expectation has been strongly dismissed by several interviewees situated lower in the framework, who point out that the potato in fact is already highly efficient crop compared to contemporary hybrid crops like maize.

Other than the start-up company, who put a precise number on the improvements to come, other interviewees in the top right of the map generally mix firm statements about the impact of the technology with careful notes emphasizing uncertainty about what changes will be brought about exactly. As the government official noted: "it is too early to tell how exactly this will developed, but it will certainly bring about changes" (interview 29 July 2016).

Interviewees with high expectations seldom addressed the technical barriers to hybrid breeding that made interviewees with low expectations question the impact of hybrid breeding. They did however regularly mention and respond to other obstacles articulated by these actors. For instance, the government official highlighted that current European regulations only apply to potato tubers and hence prohibit the trade in True Potato Seeds. However, in his view these obstacles can be taken away: the government is already addressing the limitations of European regulations in Brussels. The government official also did not worry about a future scenario in which power and knowledge in the potato sector shifts to large multinationals, as monopolies could be prevented through national competition law (interview 29 July 2016).

Actors with high expectations for the sector, in other words, were generally optimistic that systemic barriers could be overcome: "of course all this still should be turned into reality, but we firmly believe that it is possible" (interview 29 July 2016).

One of the most important obstacles for hybrid breeding to change the potato sector mentioned by these interviewees is the actual resistance from the existing potato sector. The government and the start-up both noted that the entire potato sector will only believe it once they see it. But these expectations seem to be governed in a different way than the other obstacles. Interviewees in the top right of the framework persistently spoke of the actors who articulated these expectations as 'the establishment' who may be too caught up in well-established ways of potato breeding (interviews 29 July 2016 \& 29 March 2016). The start-up company regularly drew upon this resistance to portray themselves in a way that resembles Schumpeter's image of the heroic innovators, forging ahead despite scepticism from conservative sector, achieving what others deem impossible (Schumpeter, 1934). They thereby co-opt existing low expectations for hybrid breeding into their own narrative.

The lobby organization emphasized that hybrid breeding is part of a larger trend in which technological advances, including marker assisted breeding and genetic modification, drive the potato sector to follow the route of vegetable breeding (interview 23 June 2016). However, we also encountered the frame that hybrid breeding technology alone will be behind this movement. For instance, the government official argued:

"Thus far nobody succeeded in making the potato more robust. We still have 'bintje' potatoes that were developed 110 years ago (...) and in the United States they have a variety that is 140 years old. Breeding potatoes is incredibly difficult because of its genetic make-up. But now we have a tool in our hands with which we can breed varieties in a targeted way" (interview 29 July 2016).

And the minister of Economic Affairs wrote in a letter to the Dutch parliament:

"the potato is the world's fourth most important crop in terms of turnover. And yet innovation in this crop has nearly stood still for already 60 years; 'Bintje' is still the biggest variety in Europe” (Kamp, 2014).

The expectation is that hybrid breeding can provide a technological solution to urgent problems within the sector, in particular its vulnerability to diseases like late blight, which conventional breeding thus far failed to solve. Hybrid breeding promises a technological fix by reducing the genetic complexity of potatoes and hence allowing for faster and more precise breeding practices. From this perspective, the sector will automatically change to accommodate the benefits of hybrid breeding. The changes this may bring to the sector are simply deemed desirable in the face of these challenges.

There were however diverging expectations about what these changes mean for the competitiveness of the Dutch potato sector. The government expected hybrid breeding to strengthen the Dutch potato breeding sector as the successful potato multiplication system in the Netherlands cannot easily be copied elsewhere (interview 29 July 2016), whereas the lobby organization considered outsourcing as significant threat to Dutch interests in the long term. In this scenario seed tubers growing as well as breeding could be done in countries like Algeria and Bangladesh, where labour is cheaper (interview 23 June 2016).

However, not all interviewees that believe in the disruptive power of hybrid breeding see only positive effects. The interviewee from the environmental NGO described two possible future scenarios, one positive and one negative, depending on who will develop and implement the technology. On the one hand, he worried that "large industrial chemical powers" may take control of the sector by obtaining or purchasing patents, contributing to further integration of the potato chain. This would mean hybrid breeding will be used to create "more of the same": potato varieties that fit well in a style of farming based on "large industrial monocultures". On the 
other hand, if the technology would be widely available, it could be used to develop more robust potatoes (interview 15 July 2016 ).

The environmental NGO has been situated in Box C but can be considered somewhat of an outlier, as their expectations for the sector were very high, but their expectations for society are more moderate than those of the government and start-up company. The interviewee from the environmental NGO used many of the same arguments as the stakeholders from the organic sector but had higher expectations concerning the societal impact in his positive scenario of the future: robust hybrid potatoes could modestly contribute to diverse ecological systems - agricultural systems in which agriculture and nature strengthen each other and move away from monocultures. This contrasts to his views on genetically modified crops, to which the environmental NGO has fundamental objections (interview 15 July 2016).

\subsubsection{High expectations for society}

Interviewees on the top right of the framework, particularly the start-up company and the government official, also held very high expectations of the contribution of hybrid breeding to social challenges. Sustainability is a good example of this. The start-up expected hybrid breeding to strongly contribute to ecological sustainability because it becomes possible to quickly breed disease resistant potatoes, thereby limiting the need for pesticides (potato currently requires relatively large amounts of pesticides) (interview 29 March 2016). However, the main societal expectation pertains to its impact on global food security, especially in developing countries. This expectation is revolutionary indeed: the start-up company claimed that their "significantly cheaper and better starting material will enable escape from "poverty trap"” (Solynta, 2016b) and a well-known Dutch politician allegedly exclaimed that "finally the existing breeding tools can be used in potato, this will change the world (...) [and result in] a second green revolution" (Solynta, 2016c).

These expectations usually start with the observation that the potato is already well-positioned to contribute to food security. Compared to other staples like rice, maize, and cassava, the potato has relatively high yields, requires little water, and is a rich source of vitamins and minerals. Interviewees with high societal expectations argue that this potential has not been realized so far because of several hurdles that cannot be overcome by means of conventional breeding, but that hybrid breeding offers a solution to exactly these problems. The start-up describes this in terms of their 'societal responsibility':

"It would be unacceptable to ignore developing countries when working to innovate the third food crop in the world. So that is one of the reasons why we are currently active in Eastern Africa, so to see if we can already implement this technology there (...) because the societal need is much larger there" (interview 29 March 2016).

This especially concerns the expectation that hybrid breeding enables the development of new potato varieties that are less prone to disease and that are well-adapted to the local circumstances in developing countries. For instance, the start-up writes on their website that "the biggest constraint in the developing world is healthy seed tubers" (Solynta, 2016a) and that hybrid breeding through seeds can help to provide "excellent starting material resulting in far richer crops" (Solynta, 2016b). Also the nutritional content of potatoes fuelled expectations of development benefits of hybrid breeding, especially for the government. Due to its genetic complexity, potato breeding efforts thus far have hardly focused on improving nutritional contents. Hybrid breeding could in this way make the potato even more effective in fighting food insecurity (interview government 29 July 2016). Hybrid breeding is thus presented as a technological solution to an urgent societal problem.

Although these high expectations were only articulated by two actors, we have seen that they have become performative. For the government these potential societal benefits were an important reason to back the start-up company. In writing to the Dutch parliament in 2016, the minister of Economic Affairs justified the government's financial and political support to the start-up company by noting that in doing so the government underlines "the important Dutch contribution to global food security" (Kamp, 2016). The start-up company itself has led several missions to Africa and Asia to explore the potential of hybrid breeding in development contexts (e.g. Danial, De Vries, \& Lindhout, 2016) and have meanwhile even conducted a first trial with diploid potato hybrids in the Democratic Republic of Congo (de Vries, Ter Maat, \& Lindhout, 2016).

Interestingly, whereas these two interviewees did explicitly counter arguments of those that do not expect a large impact on the sector, these two interviewees did not respond to the many obstacles articulated by other actors who are more hesitant about the potential contribution of hybrid breeding to global food security. In particular, these actors questioned the ability of developing countries to set up multiplication systems that could keep the potato disease-free. The start-up company and government official hardly explicitly addressed this. Another important concern articulated by other actors is that private corporations may use the technology to breed new varieties that fail to address urgent societal needs. Although this was acknowledged by the government official, he countered that the government aims to ensure the development of socially relevant varieties by co-opting corporations in government-supported research programmes with multiple partners, in which the start-up company already collaborates (interview 29 July 2016).

Nevertheless, the start-up company and government official did seem keenly aware of the challenges that such changes would entail. The report of the missions to Africa for instance argues that the need to disseminate knowledge, technologies and material required for growing potato hybrid seeds will be a great challenge and that "the usage of hybrid potato seeds in East Africa can only successfully be achieved in coordinated actions of private and public partners with clear roles, tasks and responsibilities of each partner" (Danial et al., 2016, p. 1). The report furthermore highlights that starting R\&D activities in some African countries is too risky due to attacks on private companies, strong government domination, or lack of stable organizations.

Yet despite making such cautious notes, in a press release hardly four months later the start-up company nevertheless concluded that "potatoes grown from seed may solve hunger in Africa" (ANP Pers Support, 2017). It seems that for the interviewees with the highest expectations, ideas about what the world should look like are the starting point for expectations and that potential obstacles 
can be overcome along the way. As the start-up company noted, if we want to realize their revolutionary objectives, actors "simply have to put aside all their preconceptions" (interview 29 March 2016).

\section{Discussion of results}

The framework for mapping expectations demonstrates a clear curve. On the bottom left (Box A, Fig. 1) we see a competitor and a farmer breeder who expect hybrid breeding to have little to no impact on sector and society. The farmer breeder is perhaps the actor that stands to lose most if hybrid breeding indeed proves successful, as many actors expect this development to diminish the importance of farmers breeders in the sector. Also the large trading company could stand to lose if the start-up becomes very successful with this new technology. However, this cannot fully explain their position at this corner of the framework. After all, if hybrid breeding indeed proves a disruptive innovation that would harm the trading cooperation's interests, it would be sensible for them to start investing in hybrid breeding themselves- as other potato trading companies have done in the past years (e.g. van der Woude, 2016; Verbeek, 2017). Instead their position at the corner of the framework could also be attributed to the technological barriers that they perceive: if hybrid is not technologically feasible, then little impact is to be expected on either the sector or society.

The middle cluster (Box B, Fig. 1) is by far the largest, among others including all university researchers, the seed tuber farmers and the organic farmer, the processing company and a trading company. Some of these actors, like the tuber farmers and the smaller rival trading company, could be negatively affected if hybrid breeding would indeed prove to be disruptive. Hence they have little interests in formulating high expectations that could become performative.

The position of at least some of these actors can further be understood by the so-called 'trough of uncertainty' (Brown \& Michael, 2003). This notion highlights that actors closely involved in the production of knowledge (like university researchers) and outsiders or competitors often have relatively modest expectations. Their position either close to knowledge production or far from the product makes it more likely for them to perceive various uncertainties - as we have seen with the various technological and societal barriers that were identified - which lowers their expectations.

At first sight, the 'trough of uncertainty' would assume that users of the innovation, like the farmers and the processing company, would have relatively high expectations. This is not the case for our interviewees. As mentioned above, the tuber farmers possibly have a negative stake in the development that could dampen their expectations. In addition, it can also be argued that many of the users we have interviewed are actually positioned relatively close to knowledge production as well - the tuber farmers own a highly innovative company in the production of potato starting material, and the interviewee from the processing company is responsible for all breeding activities. In addition, all actors in Box B also have intimate knowledge about the complexity of the context in which the innovation would have to be applied - which makes it more likely for them to perceive various potential barriers to innovation.

The expectations of these potential users of the innovation are thus in line with the style of argumentation that characterizes other actors in Box B. In formulating expectations about hybrid breeding they consider the innovation in light of the existing structures of the potato sector. Hybrid breeding was subsequently assessed as an innovation that either strengthens the existing structure or is inhibited by it. The stability of sectoral structures itself was rarely questioned by these actors.

The expected constraints to hybrid breeding were also informed by what actors with moderate expectations perceived to be specific characteristics of the potato and the potato sector, as compared to other crops and their sectors. According to actors in this cluster, innovations like hybrid breeding have a harder time to succeed with potato because it is distinct in the complexity of its genome and the long time it takes to get from the first cross to the market. Within this context, actors with modest expectations for the sector regularly describe the start-up company and the government as outsiders that lack intimate knowledge about the potato and the potato sector, and are likely to forget that potato cannot be improved like other crops. According to them, potatoes already are quite successful, for instance in terms of having a high dry matter percentage. As one of the university researchers succinctly put it: "it is not potato that is lagging behind, but other crops that are catching up with the potato" (interview university 16 June 2016 ).

This conception, in turn, may be explained by the relatively conservative nature of the potato sector in the Netherlands, another issue repeatedly brought up by different interviewees. Although we certainly do not think such a label can unequivocally be applied to the sector as a whole, which has successfully developed and applied innovations ranging from genetic modification to drones and from marker-assisted breeding to hydroponics, it is true that the core of potato breeding has largely remained unchanged for many decades.

On the top right of the framework (Box C in Fig. 1), finally, we see the innovators and the government ministry. The start-up naturally has a direct interest in articulating futures in which the sector is sufficiently changed to create space for the emergence of their product, while simultaneously their own activities are informed by these expectations. The government and to a lesser extent the lobby association also had high expectations for both the sector and society. In stark contrast to actors with moderate expectations, these actors did not take the existing structure of the existing potato sector as their starting point but departed from urgent sector-wide problems for which hybrid breeding may offer a solution. An important difference we see with the actors with low expectations is that their expectations of what the world should look like, about what problems require solutions, are not overridden by constraining views of path dependency. For these interviewees, hybrid breeding technology is a sufficiently promising technology for various obstacles to be overcome.

We found a clear curve from low expectations for sector and society, to modest expectations for the sector and low expectations for society, to high expectations for both. We would like to emphasize that this may not be unequivocally the case for other innovations, in other sectors, and in other circumstances. It may not be unlikely, for example, that some innovations in other sectors would be paired with high expectations for society and low expectations for the sectoral impact, resulting in a rather different distribution of actors in the mapping framework. For example, in case an innovation with potentially large societal impacts is 
developed by a dominant market player, hence fortifying its dominant position in the sector, it is perfectly imaginable that most actor expectations will be clustered at the bottom-right of the framework, especially if it concerns an innovation that requires few changes in existing corporate practices. Further research is hence required for determining under what conditions actors take different positions on the mapping framework in case of other innovations in different sectors. Comparing the positioning of actors with regards to different innovations and sectors can help to further shed light on such expectation dynamics.

\section{Conclusions}

The emergence of hybrid potato breeding in the Netherlands is surrounded by a plethora of different and often contradicting expectations about the impact of hybrid breeding on the potato sector and society. These expectations are thus far articulated in rather unconnected forums, often within the walls of individual organizations. In situations where more structured settings raise high entry barriers, it can be difficult to oversee the diverging claims about the future impact of an innovation and to understand what is at stake. In this context, we have developed a framework for mapping the expectations of stakeholders about hybrid potato breeding. This framework can be used to visualize the relative positions of actors, taking into account both their expectations for the impact of the innovation on the sector and society. We have applied this framework to provide an overview of expectations regarding hybrid potato breeding and gain insight into the various arguments informing the positions of various actors. As such, this framework provides a good starting point for an informed debate about this potentially transformative innovation, and as such can be understood as a tool for governing expectations in previously unstructured settings where conventional structured settings pose entry-barriers that are too high.

The framework particularly provides insight into various ways that actors are talking at cross-purposes. The expectations, as it were, were part of a dialogue of the deaf. Using the framework for instance showed that actors with small and modest expectations focus on dismantling the claim that potatoes will be grown directly from seed, while this possibility of hybrid breeding is not considered to be the most important for those who expect hybrid breeding to have pervasive consequences for the sector. And it for instance showed that actors with high expectations try to dismantle the concerns of others by focusing on the feasibility of the technology, while for most actors with low or modest expectations the main concern is that a fast turnover of varieties is limited by institutional and organizational factors in farming and processing potatoes. This suggests that further investigating and discussing these latter factors can help to generate more robust expectations that incorporate the expectations of different actors. Another example of such a dialogue of the deaf was that different actors from the sector expected the environmental NGO to oppose hybrid breeding technologies whereas we found this not to be the case whatsoever - they instead share values of sustainability and food security with for instance the start-up company. Applying the mapping framework in this case opens up opportunities for actors to step outside the confines of their own organizations and seek collaboration in surprising directions. By bringing such a lack of understanding of one another's position into view, the mapping framework provides a solid basis for a more informed debate, and possibly for the articulation of more robust expectations that take into account the diverging assessments of other actors.

The framework further can be used to bring into view shared themes among different actors. We earlier noted that the willingness by actors to participate in foresight and scenario activities (and to collaborate towards a joint goal more generally) largely depends on the existence of a shared agenda, often revolving around objectives like sustainability, competitiveness, or health. While the actors in the field perceived such a shared agenda to be absent in relation to hybrid breeding, the mapping tool has brought to light several concerns that were shared by the different actors. Most notable amongst these were the types of agricultural systems for which hybrid breeding may be put to use (e.g. large-scale industrial farming versus small-scale diversified farming), the similarities and differences between potato and vegetable breeding (e.g. potato increasingly resembling vegetable breeding versus potato remaining a unique breeding practice), and more generally the possible role of potato breeding in issues of food security. In the case of each of these themes we found that actors articulated strongly diverging expectations while sharing similar concerns. Applying the mapping framework hence revealed that shared concerns about the future of agricultural farming systems and the role of potato in global food security can offer a fruitful starting point for further debate and collaboration among actors who previously worked under the assumption that a shared agenda was lacking.

We would argue that such a framework could be useful in the process of articulating socially robust expectations in unstructured settings in other domains. The insights gained from using this framework creates room for discussion about what is at stake for different actors. Mapping the differences and similarities in a systematic way hence helps to bring into focus the questions that are most important - whether these questions pertain to the technological feasibility of an innovation, the creative destruction that an innovation may bring about for a particular sector, or normative implications of the way agricultural systems are organized.

\section{References}

Almekinders, C. J. M., Mertens, L., van Loon, J. P., \& Lammerts van Bueren, E. T. (2014). Potato breeding in the Netherlands: A successful participatory model with collaboration between farmers and commercial breeders. Food Security, 6(4), 515-524.

ANP Pers Support (2017). Potatoes grown from seeds may solve hunger in Africa. (Accessed 31.03.2017) https://www.perssupport.nl/persbericht/7ca632af-1ef0-4cb59d7b-9f113f7d113b/potatoes-grown-from-seeds-may-solve-hunger-in-africa.

Bijker, W. E. (1995). Of bicycles, bakelites, and bulbs: Toward a theory of sociotechnical change. Cambridge, MA: MIT Press.

Borup, M., Brown, N., Konrad, K., \& Van Lente, H. (2006). The sociology of expectations in science and technology. Technology Analysis \& Strategic Management, 18(34), 285-298.

Brown, N. (2003). Hope against hype - Accountability in biopast, present and futures. Science Studies, 16(2), 3-21.

Brown, N., \& Michael, M. (2003). A sociology of expectations: Retrospecting prospects and prospecting retrospects. Technology Analysis \& Strategic Management, 15(1), $3-18$. 
Brown, N., Rapport, B., \& Webster, A. (2000). Contested futures: A sociology of prospective techno-science. Aldershot: Ashgate Press.

Centraal Bureau voor de Statistiek (CBS) (2015). CBS statweb. [database].

Danial, D., De Vries, M., \& Lindhout, P. (2016). Exploring the potential of hybrid potato cultivars in East Africa. (Accessed 31 March 2017) http://knowledge4food.net/wpcontent/uploads/2017/02/161130-Report-Solynta-mission-to-East-Africa.pdf.

David, P. (1985). Clio and the economics of QWERTY. American Economic Review, 75(2), 332-337.

de Vriend, H., \& Lammerts van Bueren, E. (2014). Aardappelveredeling: Oude eigenheimers in de puree? In M. Kreijveld, J. van Deuten, \& R. van Est (Eds.). De kracht van platformen. Nieuwe strategieën voor innoveren in een digitaliserende wereld. Deventer: Vakmedianet.

de Vries, M., Ter Maat, M., \& Lindhout, P. (2016). The potential of hybrid potato for East-Africa. Open Agriculture, 1(1), $151-156$.

Food and Agriculture Organization of the United Nations (FAO) (2015). FAO statistical databases. [database].

Kamp, H. G. J. (2014). Innovatiebeleid. Brief van de minister van economische zaken aan de voorzitter van de Tweede Kamer der Staten-Generaal Identifier kst-33009-7. https://zoek.officielebekendmakingen.nl/kst-33009-7.html (Accessed 31 March 2017).

Kamp, H. G. J. (2016). Innovatiebeleid. Brief van de minister van economische zaken aan de voorzitter van de Tweede Kamer der Staten-Generaal Identifier kst-33009-15. https://zoek.officielebekendmakingen.nl/kst-33009-15.html (Accessed 31 March 2017).

Kloppenburg, J. R. (2004). First the seed. The political economy of plant biotechnology. Madison: University of Wisconsin Press.

Konrad, K., \& Alvial Palavicino, C. (2017). Evolving patterns of governance of, and by, expectations: The graphene hype wave. In D. Bowman, E. Stokes, \& A. Rip (Eds.). Embedding new technologies into society: A regulatory, ethical \& societal perspective. Singapore: Pan Stanford.

Michael, M. (2000). Futures of the present: From performativity to prehension. In N. Brown, B. Rappert, \& A. Webster (Eds.). Contested futures. A sociology of prospective techno-science. Aldershot: Ashgate.

Nederlandse Aardappel Organisatie (2017). Pootgoedexport in tonnen oogst 2016. [database] http://www.nao.nl/nl/markt/exportcijfers (Accessed 31 March 2017) .

Nerlich, B., \& Halliday, C. (2007). Avian flu: The creation of expectations in The interplay between science and the media. Sociology of Health \& Illness, 29(1), 46-65.

Rabobank (2015). Thema-update: Pootaardappelsector. Rabobank Cijfers \& Trends. (Accessed 31 March 2017) https://www.rabobank.nl/images/q559-tupootaardappelen_29868091.pdf.

Schumpeter, J. A. (1934). The theory of economic development. An inquiry into profits, capital, credit, interest, and the business cycle. Cambridge, MA: Harvard University Press.

Selin, C. L. (2008). Sociology of the future: Tracing stories of technology and time. Sociology Compass, 2(6), 1878-1895.

Solynta (2017). About Solynta. (Accessed 31 March 2017) http://solynta.com/index.php/about-solynta/.

Solynta (2016a). Paradigm shift. (Accessed 31 March 2017) http://web.archive.org/web/20161031150314/http://www.solynta.com/hybrid-potato-breeding/ paradigm-shift.

Solynta (2016b). Sustainability. (Accessed 31 March 2017) http://web.archive.org/web/20161031151722/http://www.solynta.com/csr.

Solynta (2016c). News. (Accessed 31 March 2017) http://web.archive.org/web/20161031145255/http://www.solynta.com/media/news.

Truffer, B., Voß, J. P., \& Konrad, K. (2008). Mapping expectations for system transformations: Lessons from sustainability foresight in German utility sectors. Technological Forecasting and Social Change, 75(9), 1360-1372.

Tutton, R. (2011). Promising pessimism: Reading the futures to be avoided in biotech. Social Studies of Science, 41(3), 411-429.

van der Lee, H. (2016). Hybride aardappel moet zich bewijzen. De Akker, 9, 4-7.

van der Woude, C. (2016). KWS gaat volledig voor hybride aardappel. Boeren Business. Accessed 31.03.2017 http://www.boerenbusiness.nl/aardappelen/artikel/ 10869204/kws-gaat-volledig-voor-hybride-aardappel.

van Dijk, L., Edelenbosch, R., \& Beumer, K. (2016). Potato breeding in the Netherlands. Wageningen.

van Lente, H., \& Rip, A. (1998). Expectations in technological developments: An example of prospective structures to be filled in by agency. In C. Disco, \& B. J. R. Van der Meulen (Eds.). Getting new technologies together. Berlin: Walter de Gruyter.

Verbeek, J. (2017). Aardappelsector staat aan vooravond revolutie. Het Financiële Dagblad15 27 March 2017. 